\title{
Reducing the risk of heart failure in diabetes mellitus: review of new therapeutics
}

\author{
Shreeharsh Godbole ${ }^{1}$, Shreerang Godbole ${ }^{2 *}$
}

\author{
${ }^{1}$ Department of Medicine, Dr. Vasantrao Pawar Medical College, Hospital and Research Centre, Adgaon, Nashik, \\ Maharashtra, India \\ ${ }^{2}$ Department of Endocrinology, Institute for Treatment, Research in Diabetes and Endocrinology, Pune, Maharashtra, \\ India
}

Received: 07 February 2019

Accepted: 12 March 2020

\section{*Correspondence:}

Dr. Shreerang Godbole,

Email: instridepune@gmail.com

Copyright: ( $)$ the author(s), publisher and licensee Medip Academy. This is an open-access article distributed under the terms of the Creative Commons Attribution Non-Commercial License, which permits unrestricted non-commercial use, distribution, and reproduction in any medium, provided the original work is properly cited.

\begin{abstract}
Diabetes mellitus (DM) and heart failure (HF) are closely related: patients with diabetes have an increased risk of developing HF and those with HF are at higher risk of developing diabetes. When the two diseases are considered individually, HF has a much poorer prognosis than diabetes mellitus; therefore, treatment of HF is a priority in these group of patients. There are many drugs now available to achieve glycemic control in individuals with DM. However, as we enter an era of personalization in the management of DM, the next challenge will be the identification of therapeutic strategies that will not only achieve and maintain glycemic control, but that will also reverse existing complications. Given the high prevalence of HF in DM, there is a strong imperative to advance this field, with the view of identifying robust strategies that will not only improve long-term outcomes in subjects with DM and HF but also limit the likelihood of developing HF in the first place. Newer therapies like sodium-glucose transport protein- 2 inhibitors (SGLT-2 I) and sacubitril or valsartan have shown potential benefit for reducing the risk of heart failure in diabetic population. This review will summarize the new therapeutics to reduce the risk of HF in patients with DM.
\end{abstract}

Keywords: Diabetes mellitus, Heart failure, Metformin, SGLT-2 inhibitors

\section{INTRODUCTION}

The prevalence of type 2 diabetes mellitus (T2DM) has risen consistently over the past years. International Diabetes Federation, 2019 reported that India ranks second in the world for the number of diabetes cases $(77$ million), and has anticipated this number to reach 134.2 million by $2045 .^{1}$

Concerns about cardiovascular disease (CVD) in T2DM have traditionally focused on atherosclerotic vasculoocclusive events, such as myocardial infarction, stroke, and limb ischemia. However, one of the earliest and most serious CVD in patients with diabetes is heart failure
(HF). Diabetic patients have an increased risk of developing HF because of the abnormal cardiac handling of glucose and free fatty acids, and because of the effect of the metabolic derangements of diabetes on the cardiovascular system. Following its onset, patients experience a striking deterioration in their clinical course, which is marked by frequent hospitalizations and eventually death. Heart failure and diabetes are linked pathophysiologically. T2DM and HF are each characterized by insulin resistance and are accompanied by the activation of neurohormonal systems (norepinephrine, angiotensin II, aldosterone, and neprilysin). The two disorders overlap; diabetes is present in 35 to $45 \%$ of patients with chronic heart failure (CHF), 
whether they have a reduced or preserved ejection fraction. $^{2}$

A wealth of epidemiological evidences establish that diabetes mellitus (DM) is highly common amongst patients with $\mathrm{HF}$, especially those with heart failure and preserved ejection fraction (HFpEF), and patients with the both conditions have an increased risk of mortality compared with patients without diabetes or $\mathrm{HF}^{3}$ As per the Framingham heart study, HF was shown to be twice as common in men with diabetes and five times more prevalent in women with diabetes between the ages of 45 and 74 years when compared with age-matched nondiabetic controls, and, in those aged $\geq 65$ years, there was a fourfold increase in the prevalence of HF in men with diabetes and an eightfold increase in women with diabetes. ${ }^{4}$ Therefore, an exponential surge has seen in the combined diagnoses of T2DM and HF. On acknowledging these two diseases individually, HF has a much poorer prognosis than diabetes mellitus, therefore $\mathrm{HF}$ has to be a priority for treatment in patients presenting with the two conditions. ${ }^{4}$ In this present review we document relationship between $\mathrm{HF}$ and T2DM and the potential therapies to both prevent and treat $\mathrm{HF}$ are discussed, in addition to the positive effects of newer therapies like sodium- glucose transport protein-2 inhibitors (SGLT-2 i) and sacubitril or valsartan for reducing the risk of heart failure in diabetic population.

\section{ETIOPATHOLOGY OF HF IN DM}

\section{The cardio toxic tetrad}

The coexistence of coronary artery disease (CAD), left ventricular hypertrophy $(\mathrm{LVH})$ and a specific diabetic cardiomyopathy, normally referred to as the cardiotoxic triad, leads to biochemical, anatomical and functional alterations in cardiomyocytes and cardiac tissues, and was originally thought to be the most appropriate explanation for the development of left ventricular dysfunction; however, the addition of fluid overload, which increases ventricular pressure in a stiffened ventricle, has also been suggested to extend the triad to the cardiotoxic tetrad (Figure 1). ${ }^{3,5}$ The combination of ischaemic heart disease, LVH and diabetic cardiomyopathy in conjunction with an extracellular volume expansion, which may be resistant to the action of atrial natriuretic peptides, initially leads to diastolic dysfunction, which is very common in people with type 2 diabetes. ${ }^{6}$

\section{Effect of glycemic variability on HF in T2DM}

Glucose variability is known as one of the factors associated with adverse CVD outcomes for patients with T2DM. In a prospective, longitudinal study conducted to assess the prognostic impact of long-term glycemic variability $(\mathrm{GV})$ on clinical outcomes in 902 patients with HF and T2DM, HbA1c variability was independently and similarly predictive of combined endpoints of death and $\mathrm{HF}$ readmission regardless of ejection fraction. ${ }^{7}$ Yokoto et al assessed the impact of GV on left ventricular (LV) diastolic function in 100 asymptomatic T2DM patients with preserved LV ejection fraction (LVEF) without coronary artery disease. Mitral inflow E and mitral e' annular velocities (E/e') in patients with high $\mathrm{GV}(\geq 35.9$ $\mathrm{mg} / \mathrm{dl})$ were significantly higher than that in patients with low GV (<35.9 mg/dl) (11.3 \pm 3.9 vs. 9.8 $\pm 2.8, \mathrm{p}=0.03)$. Furthermore, multivariate logistic regression analysis showed that $\mathrm{GV} \geq 35.9 \mathrm{mg} / \mathrm{dl}$ was an independently associated factor of E/e' $>14$ as well as age. Thus, reducing $\mathrm{GV}$ may have a potential for a new therapeutic strategy for the prevention of HF in diabetic patients. ${ }^{8}$

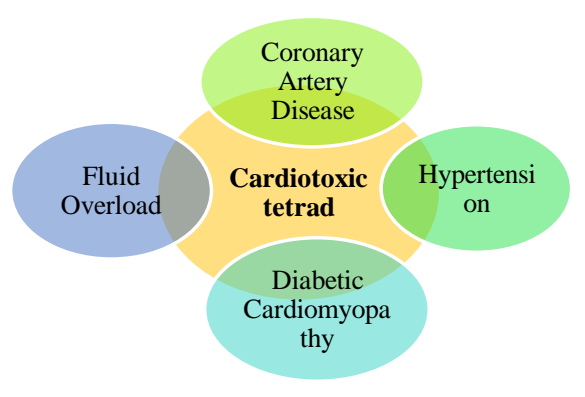

Figure 1: The cardiotoxic tetrad. ${ }^{5}$

\section{Poor glycaemic control and risk of HF in DM}

Appropriate glycaemic control can reduce the risk of developing HF. UKPDS study showed that every $1 \%$ reduction in $\mathrm{HbA} 1 \mathrm{c}$ was associated with a $16 \%$ decrease in the development of $\mathrm{HF}$ in people with new-onset diabetes. ${ }^{9}$ However, intensive glycaemic control in this study did not reduce admissions to hospital with HF. ${ }^{10}$ Tight glycaemic control also did not reduce $\mathrm{HF}$ in the action to control cardiovascular risk in type 2 diabetes trial and action in diabetes and vascular disease: preterax and diamicron MR controlled evaluation trial and veterans affairs diabetes trial. ${ }^{11-13}$ In a Swedish prospective casecontrol study of 33402 patients with type 1 diabetes, poor glycaemic control significantly increased the risk of hospitalization due $\mathrm{HF}$ by fourfold compared to population based controls. HbA1c remained a risk factor for the development of HF even after adjustment for renal disease, showing a steep increase with poor glycaemic control. ${ }^{14}$

\section{Therapies to reduce the risk of HF in patients with DM}

Therapies to reduce the risk of HF in patients with DM can be broadly classified as: oral anti-hyperglycaemic agents (OHA) and non-diabetic medications.

\section{OHA THAT MAY PREVENT OR AMELIORATE HF}

\section{Metformin}

Metformin, first line OHA for T2DM, and results in a lower risk of death and HF hospitalization compared with 
insulin and sulfonylureas. ${ }^{15-17}$ Furthermore, 2019 European Society of Cardiology (ESC) guidelines on diabetes, pre-diabetes, and cardiovascular diseases developed in collaboration with the European Association for the Study of Diabetes (EASD) has endorsed the metformin at all stages of HF with preserved or stable moderately reduced renal function (i.e. eGFR >30 $\mathrm{ml} / \mathrm{min}^{18}$

Table 1: Therapies to reduce the risk of $\mathrm{HF}$ in patients with DM.

\begin{tabular}{|c|c|}
\hline $\begin{array}{l}\text { Therapies to reduce } \\
\text { the risk of } \mathrm{HF} \text { in } \\
\text { patients with DM }\end{array}$ & Drugs \\
\hline \multirow{2}{*}{ ОНА } & Metformin \\
\hline & SGLT-2 i \\
\hline \multirow{4}{*}{$\begin{array}{l}\text { Non-diabetic } \\
\text { medications }\end{array}$} & $\begin{array}{l}\text { RAAS inhibitors (ACE } \\
\text { inhibitors, ARB, MRA, ARNI }\end{array}$ \\
\hline & $\begin{array}{l}\text { Beta blocker (metoprolol, } \\
\text { carvedilol) }\end{array}$ \\
\hline & Ivabradine \\
\hline & Statin (rosuvastatin) \\
\hline \multicolumn{2}{|c|}{$\begin{array}{l}\text { SGLT-2 i: Sodium- glucose transport protein-2 inhibitors, } \\
\text { RAAS-inhibitors: renin angiotensin aldosterone system } \\
\text { inhibitors, ACE inhibitors: angiotensin-converting enzyme } \\
\text { inhibitors, ARB: angiotensin receptor blocker, MRA: } \\
\text { mineralocorticoid receptor antagonist, ARNI: angiotensin } \\
\text { receptor-neprilysin inhibitors. }\end{array}$} \\
\hline
\end{tabular}

\section{SGLT2-inhibitors}

Hospital admission for heart failure has been shown to significantly reduced by $35 \%, 33 \%$ and $27 \%$ with empagliflozin cardiovascular outcome event trial in type 2 diabetes mellitus patients removing excess glucose (EMPA-REG study), canagliflozin cardiovascular assessment study (CANVAS study) and dapagliflozin effect on cardiovascular events-thrombolysis in myocardial infarction (DECLARE-TIMI) 58 trial respectively. The mechanisms by which sodium glucose transporter-2 inhibitors (SGLT-2 i) mediate these benefits are not understood. However potential mechanisms that have been proposed include increased natriuresis, reduced blood pressure, renal protection and a modest effect to increase circulating ketones, which might improve myocardial energetics. ${ }^{19}$ More recently, reduction in plasma volume without concomitant compensating neurohormonal activation and a mitochondrial protective effect has been postulated as potential mechanism mediating the reduction of heart failure events. ${ }^{20}$ In light of evidence, 2019 ESC Guidelines on diabetes, prediabetes, and cardiovascular diseases developed in collaboration with the EASD recommended SGLT2 i (empagliflozin, canagliflozin, or dapagliflozin) to lower risk of $\mathrm{HF}$ hospitalization in patients with DM. ${ }^{18}$ Initial results from empagliflozin comparative effectiveness and safety (EMPRISE) real-world evidence study shows empagliflozin was linked with lower risk for hospitalization for HF compared with DPP-4 inhibitors in people with type 2 diabetes with and without CVD. The full EMPRISE study will deliver a clinical representation of empagliflozin in routine clinical practice comprising comparative effectiveness, safety and healthcare resource utilisation and cost outcomes compared with DPP-4 inhibitors. $^{21}$

\section{HF THERAPY IN PATIENTS WITH DM}

\section{Renin-angiotensin-aldosterone system inhibitors}

Activation of RAAS in diabetes mellitus may also contribute to inflammation, cardiac fibrosis, and oxidative stress which all contribute to cardiac remodeling, and could be reversed or prevented by RAAS blockade. Thus, ACE inhibition and Ang II (angiotensin II) type 1 receptor blockade remain first line therapy for CVD prevention in patients with diabetes mellitus. Angiotensin converting enzyme inhibitors (ACEIs) and angiotensin receptor blockers (ARBs) have similar treatment effects in patients with HFrEF, with and without DM. ${ }^{22,23}$ RAAS blockers should be started at a low dose and up-titrated to the maximally tolerated dose. ${ }^{24}$

Increased aldosterone signaling has been implicated in $\mathrm{HF}$, diabetic cardiovascular injury including diabetic cardiomyopathy and may also play a role in the pathophysiology of insulin resistance. Inhibition of aldosterone receptor signaling with eplerenone may reduce indices of inflammation and markers of insulin resistance. Thus, it would be of interest to determine metabolic and cardiovascular outcomes (including $\mathrm{HF}$ incidence) in high-risk subjects with diabetes mellitus treated with aldosterone receptor antagonists. ${ }^{25}$ Mineralocorticoid receptor antagonist (MRAs) has shown to reduce the death and HF hospitalization in HFrEF. ${ }^{26} \mathrm{In}$, eplerenone post-acute myocardial infarction heart failure efficacy and survival study (EPHESUS), eplerenone reduced the rate of mortality among patients with acute MI complicated by LV dysfunction and HF symptoms. ${ }^{27}$

Natriuretic signaling has recently been shown to promote energy expenditure and augment systemic insulin sensitivity. Moreover, reduced adipose tissue natriuretic peptide signaling correlated with insulin resistance. Thus, it is plausible that these mechanisms of action could increase insulin sensitivity and metabolic control in subjects with T2DM and HF. As such, it will be of interest to rigorously determine whether angiotensin receptor-neprilysin inhibitors (ARNI) use could reduce the risk of $\mathrm{HF}$ progression in individuals with diabetes mellitus, particularly those at high risk for CVD and HF. ${ }^{25}$ In the prospective comparison of ARNI with ACEI to determine impact on global mortality and in heart failure trial (PARADIGM-HF) trial which included $35 \%$ of diabetic population among the patients of heart failure due to reduced $\mathrm{EF}$, the angiotensin receptor neprilysin inhibitor sacubitril/valsartan has shown superior efficacy to enalapril in the reduction of $\mathrm{CV}$ death and $\mathrm{HF}$ hospitalization in patients with $\mathrm{HFrEF}$ irrespective of glycemic status. ${ }^{28}$ Sacubitril or valsartan therapy has also resulted in a greater reduction in $\mathrm{HbA} 1 \mathrm{c}$ levels and a 
lower rate of insulin initiation over 3 year follow-up compared with enalapril in patients with DM. This evidence suggests that sacubitril/valsartan might have a metabolic benefit in HFrEF patients and proposes a significant $\mathrm{CV}$ benefit of this ARNI, irrespective of the type or etiology of HF. ${ }^{29}$

\section{Beta-blockers}

Although concerns were raised in the past about the potential increase in risk of hypoglycemia, when $\beta$ blockade is used in individuals with diabetes mellitus, there is little evidence that this is the case and contemporary clinical guidelines support the use of $\beta$ blockade in individuals with diabetes mellitus and HF. Notably, carvedilol (a combined $\beta 1 / \beta 2$ antagonist) improves both glycemic control, LVEF, and decreases oxidative stress in the failing human heart and might be the $\beta$-blocker of choice in heart failure in diabetic population. ${ }^{27}$ Beta-blockers are effective at reducing allcause death and hospitalization for HFrEF in patients with DM. ${ }^{30}$ In MERIT-HF study, metoprolol reduced the risk of hospitalization for heart failure by $37 \%$ in the diabetic group of CHF. ${ }^{31}$ Treatment benefits strongly support betablocker use in patients with HFrEF and DM.

\section{Ivabradine}

Increase in resting heart rate is a risk factor for adverse cardiovascular outcome in diabetic patients. Elsewhere, data from ADVANCE trial showed that the risks of newonset or progressive nephropathy (adjusted HR 1.16 per 10 b.p.m., 95\% CI 1.08-1.25) and retinopathy (adjusted HR, 1.11 per 10 b.p.m.; 95\% CI, 1.02-1.21) were greater in patients with T2DM and higher resting heart rates. ${ }^{12}$ Lowering heart rate with ivabradine alleviates ischemia and improves cardiac function by improving coronary filling via the prolongation of diastole and the improvement of cardiac efficiency. ${ }^{32}$ Systolic heart failure treatment with the $I_{\mathrm{f}}$ inhibitor ivabradine trial (SHIFT) which included $30 \%$ of patients with chronic systolic heart failure and diabetes, demonstrated that ivabradine reduces the risk of $\mathrm{CV}$ death or $\mathrm{HF}$ hospitalization, and HF death or admission for HF, in patients in sinus rhythm with a heart rate $\geq 70$ b.p.m. This analysis confirms the benefits of heart rate reduction with ivabradine are maintained in HF patients with diabetes as well as in those without, as has already been shown for ACE inhibitors, beta-blockers, and MRAs. ${ }^{33}$

Table 2: Summary of the clinical trials for HF outcome in diabetic population.

\begin{tabular}{|c|c|c|c|}
\hline Drug & Clinical study & Design & Results \\
\hline \multirow{3}{*}{ Metformin } & McAlister et al & $\begin{array}{l}\text { Retrospective observational } \\
\text { cohort study }\end{array}$ & $\begin{array}{l}\text { Significantly }(\mathrm{p}<0.001) \text { reduced incidence of } \\
\text { HF with metformin }\end{array}$ \\
\hline & Tzoulaki et al & $\begin{array}{l}\text { Retrospective cohort study } \\
\text { based on a general practice } \\
\text { database }\end{array}$ & $\begin{array}{l}\text { Compared with metformin, first- and second- } \\
\text { generation sulfonylureas increased congestive } \\
\text { HF (adjusted HR } 1.46 \text { and } 1.30 \text {, respectively) }\end{array}$ \\
\hline & Pantalone et al & $\begin{array}{l}\text { Cohort study based on } \\
\text { electronic health records }\end{array}$ & $\begin{array}{l}\text { Metformin reduced HF (HR 0.76) and } \\
\text { mortality (HR 0.54) }\end{array}$ \\
\hline Empagliflozin & EMPA-REG study & RCT, CVOT & $35 \%$ RRR of hospitalization due to HF \\
\hline Dapagliflozin & $\begin{array}{l}\text { DECLARE TIMI } \\
58\end{array}$ & RCT, CVOT & $32 \%$ RRR of hospitalization due to HF \\
\hline Canagliflozin & CANVAS & RCT, CVOT & $33 \%$ RRR of hospitalization due to HF \\
\hline ACE I- Captopril & SAVE & RCT, CVOT & $22 \% \mathrm{RR}$ of $\mathrm{CHF}$ requiring hospitalization \\
\hline $\begin{array}{l}\text { ACE I - } \\
\text { Enalapril }\end{array}$ & SOLVD & RCT, CVOT & $\begin{array}{l}22 \% \mathrm{RR} \text { of deaths attributed to progressive } \\
\text { heart failure }\end{array}$ \\
\hline ARB- Valsartan & Val-HeFT & RCT, CVOT & $\begin{array}{l}\text { RR for Hospital admission for } \mathrm{HF}=0.47(\mathrm{p} \\
<0.001)\end{array}$ \\
\hline ARB- Losartan & HEAAL & RCT, CVOT & $\begin{array}{l}\text { Losartan } 150 \mathrm{mg} \text { daily versus } 50 \mathrm{mg} \text { daily: } \\
13 \% \text { RRR of Hospital admission for HF }\end{array}$ \\
\hline $\begin{array}{l}\text { ARNI (sacubitril } \\
\text { or valsartan) }\end{array}$ & PARADIGM-HF & $\begin{array}{l}\mathrm{RCT} \text {, sacubitril/valsartan } \\
\text { versus enalapril }\end{array}$ & $\begin{array}{l}\text { sacubitril/valsartan reduced the risk of } \\
\text { hospitalization for heart failure by } 21 \% \\
\text { compared to enalapril }\end{array}$ \\
\hline $\begin{array}{l}\text { Beta blocker- } \\
\text { Metoprolol }\end{array}$ & MERIT HF & RCT & $49 \%$ RRR of death from worsening of $\mathrm{HF}$ \\
\hline Ivabradine & SHIFT & $\mathrm{RCT}$ & $\begin{array}{l}26 \% \text { RRR for hospital admissions for } \\
\text { worsening HF, 26\% RRR for death due to HF }\end{array}$ \\
\hline Rosuvastatin & CORONA & $\mathrm{RCT}$ & $\begin{array}{l}15 \% \text { RRR for hospital admissions for } \\
\text { worsening HF }\end{array}$ \\
\hline
\end{tabular}




\section{Lipid-lowering agents}

Dyslipidemia is a major risk factor for CVD in T2DM. The characteristics of diabetic dyslipidemia include high plasma TG, high low-density lipoproteins, and low highdensity lipoproteins. These changes can be attributed to increased fatty acid flux secondary to insulin resistance in adipocytes, in concert with altered hepatic lipid metabolism. While several classes of pharmacological agents are used to treat dyslipidemia, the controlled rosuvastatin multinational trial in heart failure suggested a reduction in the risk of hospitalization for $\mathrm{HF}$ by $15 \%$ to $20 \%$ in patients on rosuvastatin. The mechanism for the reduction in $\mathrm{HF}$ is not clear, but could represent reduced ischemic events or direct effects of the statin on endothelial or microvascular function. ${ }^{34}$

\section{CONCLUSION}

The pathophysiology of HF in diabetes mellitus is complex and represents a cardiovascular complication of diabetes mellitus that contributes importantly to morbidity and mortality. Given the high prevalence of $\mathrm{HF}$ in diabetes mellitus, there is a strong imperative to advance this field, with the view of identifying robust strategies that will not only improve long-term outcomes in subjects with diabetes mellitus and HF but also limit the likelihood of developing HF in the first place. For patients with diabetes and HF, metformin and SGLT2 inhibitors are anti-diabetic medications with established excellent cardiovascular safety profiles and that help reduce cardiac readmissions. Non-diabetic drugs which have documented benefits in the management of $\mathrm{HF}$ in $\mathrm{DM}$ are ACE inhibitors, ARBs, MRAs, ARNI, beta blockers, Ivabradine and lipid lowering agent such as rosuvastatin.

Future research is needed to gain further insight into the pathophysiology and therapeutic options so as to improve the prognosis of this high-risk population.

Funding: No funding sources

Conflict of interest: None declared

Ethical approval: Not required

\section{REFERENCES}

1. International Diabetes Federation. IDF Diabetes Atlas, 9th edn. Brussels, Belgium: 2019. Available at: http://www.diabetesatlas.org

2. Rosano GM, Vitale C, Seferovic P. Heart failure in patients with diabetes mellitus. Cardiac failure review. 2017;3(1):52.

3. Bell DS, Goncalves E. Heart failure in the patient with diabetes: Epidemiology, aetiology, prognosis, therapy and the effect of glucose-lowering medications. Diabetes Obesity Metabol. 2019;21(6):1277-90.

4. Kannel WB, McGee DL. Diabetes and cardiovascular disease. The Framingham study. JAMA. 1979;241(19):2035-8.
5. Gilbert RE, Krum H. Heart failure in diabetes: effects of antihyperglycaemic drug therapy. Lancet. 2015;385(9982):2107-17.

6. David S. H. Bell MB, Edison Goncalves MD. Heart failure in the patient with diabetes: Epidemiology, aetiology, prognosis, therapy and the effect of glucose lowering medications. Diabetes Obes Metab. 2019;21(6):1277-90.

7. Gu J, Pan JA, Fan YQ, Zhang HL, Zhang JF, Wang CQ. Prognostic impact of HbA1c variability on longterm outcomes in patients with heart failure and type 2 diabetes mellitus. Cardiovascular Diabetol. 2018;17(1):96.

8. Yokota S, Tanaka H, Mochizuki Y, Soga F, Yamashita K, Tanaka Y, et al. Association of glycemic variability with left ventricular diastolic function in type 2 Diabetes Mellitus. Journal of the American College of Cardiology. 2019;73(9):764.

9. Stratton IM, Adler AI, Neil HA, Manley SE, Holman RR, Turner RC, et al. Association of glycaemia with macrovascular and microvascular complications of type 2 diabetes (UKPDS 35): prospective observational study. BMJ. 2000;321(7258):405-12.

10. Control G, Turnbull FM, Abraira C, Anderson RJ, Byington RP, Chalmers JP, et al. Intensive glucose control and macrovascular outcomes in type 2 diabetes. Diabetologia. 2009;52(11):2288-98.

11. Group AS, Cushman WC, Evans GW, Byington RP, Goff DC Jr, Grimm RH Jr, et al. Effects of intensive blood-pressure control in type 2 diabetes mellitus. $\mathrm{N}$ Engl J Med. 2010;362(17):1575-85

12. ADVANCE Collaborative Group, Patel A, MacMahon S, Chalmers J, Neal B, Billot L, Woodward M, et al. Intensive blood glucose control and vascular outcomes in patients with type 2 diabetes. N Engl J Med. 2008;358(24):2560-72.

13. Duckworth W, Abraira C, Moritz T, Reda D, Emanuele N, Reaven PD, et al. Glucose control and vascular complications in veterans with type 2 diabetes. N Engl J Med. 2009;360(2):129-39.

14. Rosengren A, Vestberg D, Svensson AM, Kosiborod M4, Clements M5, Rawshani A, et al. Long-term excess risk of heart failure in people with type 1 diabetes: a prospective case control study. Lancet Diabetes Endocrinol. 2015;3(11):876-85

15. Wong AK, AlZadjali MA, Choy AM, Lang CC. Insulin resistance: a potential new target for therapy in patients with heart failure. Cardiovasc Ther. 2008;26(3):203-13.

16. Papanas N, Maltezos E, Mikhailidis DP. Metformin and heart failure: never say never again, Expert Opinion on Pharmacotherapy. 2012;13:1-8.

17. Eurich DT, Weir DL, Majumdar SR, Tsuyuki RT, Johnson JA, Tjosvold L, et al. Comparative safety and effectiveness of metformin in patients with diabetes mellitus and heart failure: systematic review of observational studies involving 34000 patients. Circulation: Heart Failure. 2013;6(3):395-402.

18. Cosentino F. 2019 ESC Guidelines on diabetes, prediabetes, and cardiovascular diseases developed in 
collaboration with the EASD. European Heart J. 2019;41(2):255-323.

19. Kenny HC, Abel ED. Heart failure in type 2 diabetes mellitus: impact of glucose-lowering agents, heart failure therapies, and novel therapeutic strategies. Circulation Res. 2019;124(1):121-41.

20. Pafili K, Papanas N. Sodium-glucose cotransporter-2 inhibitors in type 2 diabetes: a magic potion to reduce heart failure? Expert Rev Clin Pharmacol. 2019;12(8):693-5.

21. Verma S, Lam CS, Kosiborod M. Empagliflozin and Heart Failure: What Can We Learn From EMPRISE? Circulation. 2019;139:2831-4

22. Granger CB, McMurray JJ, Yusuf S, Held P, Michelson EL, Olofsson B, et al. CHARM Investigators and Committees. Effects of candesartan in patients with chronic heart failure and reduced leftventricular systolic function intolerant to angiotensin-converting-enzyme inhibitors: the CHARM-Alternative trial. Lancet 2003;362:772-6.

23. Moye LA, Pfeffer MA, Wun CC, Davis BR, Geltman $\mathrm{E}$, Hayes D, et al. Uniformity of captopril benefit in the SAVE Study: subgroup analysis. Survival and Ventricular Enlargement Study. Eur Heart J 1994;15:2-8.

24. Ryden L, Armstrong PW, Cleland JG, Horowitz JD, Massie BM, Packer M, et al. Efficacy and safety of high-dose lisinopril in chronic heart failure patients at high cardiovascular risk, including those with diabetes mellitus. Results from the ATLAS trial. Eur Heart J 2000;21:1967-78.

25. Kenny HC, Abel ED. Heart failure in type 2 diabetes mellitus: impact of glucose-lowering agents, heart failure therapies, and novel therapeutic strategies. Circulation Res. 2019;124(1):121-41.

26. Pitt B, Zannad F, Remme WJ, Cody R, Castaigne A, Perez A, et al. Randomized Aldactone Evaluation Study Investigators. The effect of spironolactone on morbidity and mortality in patients with severe heart failure. N Engl J Med. 1999;341:709-17.

27. Zannad F, McMurray JJ, Krum H, van Veldhuisen DJ, Swedberg K, Shi H, et al. Eplerenone in patients with systolic heart failure and mild symptoms. N Engl J Med. 2011;364:11-21.

28. McMurray JJ, Packer M, Desai AS, Gong J, Lefkowitz MP, Rizkala AR, et al. PARADIGM-HF Investigators and Committees. Angiotensinneprilysin inhibition versus enalapril in heart failure. N Engl J Med. 2014;371:993-1004.

29. Yandrapalli S, Andries G, Biswas M, Khera S. Profile of sacubitril/valsartan in the treatment of heart failure: patient selection and perspectives. Vascular Health Risk Management. 2017;13:369.

30. Bobbio M, Ferrua S, Opasich C, Porcu M, Lucci D, Scherillo $\mathrm{M}$, et al. Survival and hospitalization in heart failure patients with or without diabetes treated with beta-blockers. J Card Fail. 2003;9:192-202.

31. Deedwania PC, Giles TD, Klibaner M, Ghali JK, Herlitz J, Hildebrandt P, et al. Efficacy, safety and tolerability of metoprolol $\mathrm{CR} / \mathrm{XL}$ in patients with diabetes and chronic heart failure: experiences from MERIT-HF. Am Heart J. 2005;149:159-67.

32. Reil JC, Tardif JC, Ford I, Lloyd SM, O’Meara E, Komajda M, et al. Selective heart rate reduction with ivabradine unloads the left ventricle in heart failure patients. J Am Coll Cardiol. 2013;62:1977-85.

33. Komajda M, Tavazzi L, Francq BG, Bohm M, Borer JS, Ford I, et al. Efficacy and safety of ivabradine in patients with chronic systolic heart failure and diabetes: an analysis from the SHIFT trial. Eur $\mathbf{J}$ Heart Fail 2015;17:1294-301.

34. Rogers JK, Jhund PS, Perez AC, Böhm M, Cleland $\mathrm{JG}$, Gullestad L, et al. Effect of rosuvastatin on repeat heart failure hospitalizations: the CORONA Trial (Controlled Rosuvastatin Multinational Trial in Heart Failure). JACC Heart Fail. 2014;2:289-97.

Cite this article as: Godbole $\mathrm{S}$, Godbole $\mathrm{S}$.

Reducing the risk of heart failure in diabetes mellitus: review of new therapeutics. Int J Basic Clin Pharmacol 2020;9:660-5. 